\title{
Research on Decision-making Model for Maintenance Mode Risks of Equipment Components within Task Cycle
}

\author{
Jia Liu ${ }^{1,2}$, Jianwei $\mathrm{Lv}^{1, *}$ and Jianjun Yang ${ }^{1}$ \\ ${ }^{1}$ Dept of Management Science, Naval Univ. of Engineering, Wuhan 430033, China \\ ${ }^{2}$ Institute of Navy Equipment and Technology, Beijing China, 102442 \\ ${ }^{*}$ Corresponding author
}

\begin{abstract}
To develop scientific and reasonable maintenance decision-making scheme for equipment during task execution, select a suitable maintenance mode for components, control and reduce the risk of equipment failure to the maximum, this paper analyzes the basic types of maintenance mode for equipment components within task cycle, as well as their influence on the risk of equipment failure. Taking the risk, probability, consequence and detectability of failure as the decision-making indicators, the logical judgment method is employed to create the logical judgment diagram of decision-making risks for maintenance mode of equipment components within task cycle. If any maintenance mode cannot be judged through logical judgment diagram, the safety, task and economic risks are taken as the decision-making indicators, and the fuzzy theory and analytic network process are combined to build a decisionmaking model for maintenance mode risks of equipment based on analytic network process, so as to introduce the decisionmaking method for optimal maintenance mode.
\end{abstract}

Keywords-task cycle; maintenance mode; risks; decisionmaking

\section{INTRODUCTION}

Decision-making on maintenance risks has an aim to select the maintenance mode reasonably for avoiding the risk of equipment failure or reducing it to the acceptable level. First, determining the basic types of maintenance mode and their influence on the risk of equipment failure is the premise of decision-making on maintenance mode [1-4]. Now, the logical judgment in decision-making on maintenance mode is mainly applied in the reliability-based maintenance analysis, but it does not cover all risk factors and places much emphasis on economy in the analysis, so it is not suitable for the decisionmaking on task-based maintenance mode. Hence, failure risk and its factors (failure probability, consequence, detectability and maintenance difficulty) are taken as the decision-making indicators to create the logical judgment diagram for the risks of decision-making on maintenance mode of equipment components within task cycle. If any maintenance mode cannot be judged through the logical judgment diagram for risks, it is necessary to analyze the features of the maintenance mode and take the safety, task and economic risks as the decision-making indicators. Maintenance mode[5,6] involves a multiple attribute choice, so the decision-making indicators are interconnected with each other. The evaluation features fuzzy language, so the fuzzy theory is utilized with analytic network process to build a decision-making model for risks of equipment maintenance mode based on fuzzy analytic network process, so as to select the optimal maintenance mode.

\section{INFLUENCE OF MAINTENANCE MODE ON FAILURE RISK}

Based on the features of equipment maintenance guarantee within task cycle, the maintenance modes for equipment components within task cycle include post-event maintenance, state-based maintenance, preventive periodic maintenance, preventive periodic replacement and improvement maintenance. Through the analysis on measurement in the evaluation of failure risk, the main indicators of failure risk evaluation include probability of failure occurrence, detectability of failure and influence degree of consequences [7]. Among them, the influence degree of failure consequences involves the influence degree of safety, task and economic consequences. Hence, the failure risks can be classified into safety, task and economic risks based on the influence of failure consequences. Above all, the failure risk evaluation indicator system of equipment within task cycle as presented in Fig. 1.

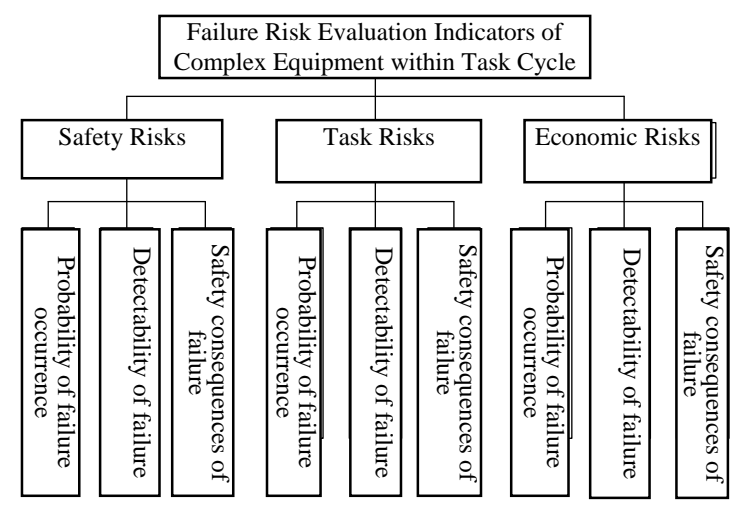

FIGURE I. FAILURE RISK EVALUATION INDICATOR SYSTEM OF EQUIPMENT WITHIN TASK CYCLE

The decision-making on maintenance mode for risks aims to select a maintenance mode reasonably for avoiding the risk of equipment failure or reducing it to the acceptable level. Therefore, it is necessary to analyze the influence of each maintenance mode on avoiding or lowering equipment failure risk. 
TABLE I. ANALYSIS ON INFLUENCE OF MAINTENANCE MODES ON EQUIPMENT FAILURE RISK

\begin{tabular}{|c|c|c|c|c|c|c|c|}
\hline No. & $\begin{array}{c}\text { Maintenance } \\
\text { Mode }\end{array}$ & Time & $\begin{array}{c}\text { Probability of } \\
\text { Occurrence }\end{array}$ & $\begin{array}{c}\text { Severity of } \\
\text { Consequence }\end{array}$ & Detectability & $\begin{array}{c}\text { Failure } \\
\text { Risk }\end{array}$ & Applicable \\
\hline 1 & $\begin{array}{l}\text { Post-event } \\
\text { maintenance }\end{array}$ & $\begin{array}{l}\text { After failure } \\
\text { occurs }\end{array}$ & No influence & No influence & No influence & $\begin{array}{c}\text { No } \\
\text { influence }\end{array}$ & $\begin{array}{c}\text { Equipment maintenance for failure with } \\
\text { less severe consequences and low risk } \\
\text { level }\end{array}$ \\
\hline 2 & $\begin{array}{c}\text { Periodic } \\
\text { maintenance }\end{array}$ & $\begin{array}{l}\text { At fixed } \\
\text { intervals }\end{array}$ & Reduce & No influence & No influence & Reduce & $\begin{array}{l}\text { Equipment maintenance for failure with } \\
\text { common probability of occurrence } \\
\text { \&severity of consequences and moderate } \\
\text { risk level }\end{array}$ \\
\hline 3 & $\begin{array}{c}\text { Periodic } \\
\text { replacement }\end{array}$ & $\begin{array}{l}\text { Within fixed } \\
\text { periods }\end{array}$ & $\begin{array}{c}\text { Reduce } \\
\text { considerably }\end{array}$ & No influence & No influence & Reduce & $\begin{array}{l}\text { Equipment maintenance for failure with } \\
\text { common probability of occurrence and } \\
\text { severity of consequences and moderate } \\
\text { risk level, but high maintenance cost }\end{array}$ \\
\hline 4 & $\begin{array}{l}\text { State-based } \\
\text { maintenance }\end{array}$ & $\begin{array}{l}\text { condition of } \\
\text { sensor and } \\
\text { monitoring \& } \\
\text { diagnosis } \\
\text { technology }\end{array}$ & $\begin{array}{c}\text { Reduce } \\
\text { considerably }\end{array}$ & No influence & Increase & Reduce & $\begin{array}{l}\text { Equipment maintenance for failure with } \\
\text { high frequency of occurrence, high } \\
\text { severity of consequences, high risk level, } \\
\text { and high maintenance cost }\end{array}$ \\
\hline 5 & $\begin{array}{l}\text { Improvement } \\
\text { maintenance }\end{array}$ & $\begin{array}{l}\text { Preparation } \\
\text { period for } \\
\text { task }\end{array}$ & $\begin{array}{c}\text { Reduce } \\
\text { considerably }\end{array}$ & $\begin{array}{c}\text { Reduce } \\
\text { considerably }\end{array}$ & $\begin{array}{c}\text { Increase } \\
\text { considerably }\end{array}$ & $\begin{array}{c}\text { Reduce } \\
\text { considerably }\end{array}$ & $\begin{array}{c}\text { Equipment maintenance for failure with } \\
\text { very high frequency of occurrence or } \\
\text { unbearable consequences, and very high } \\
\text { risk level }\end{array}$ \\
\hline
\end{tabular}

\section{DECISION-MAKING IDEA FOR RISKS OF MAINTENANCE} MODE OF EQUIPMENT COMPONENTS WITHIN TASK CYCLE

The decision-making idea for risks of maintenance mode of equipment components within task cycle is as follows: first, analyze the influence of maintenance mode on the risk of equipment failure, and employ the logical judgment method to decide the maintenance mode; second, employ the fuzzy analytic network process to decide the maintenance mode for components if their maintenance mode cannot be determined through logical judgment. The specific idea is shown in Fig. 2.

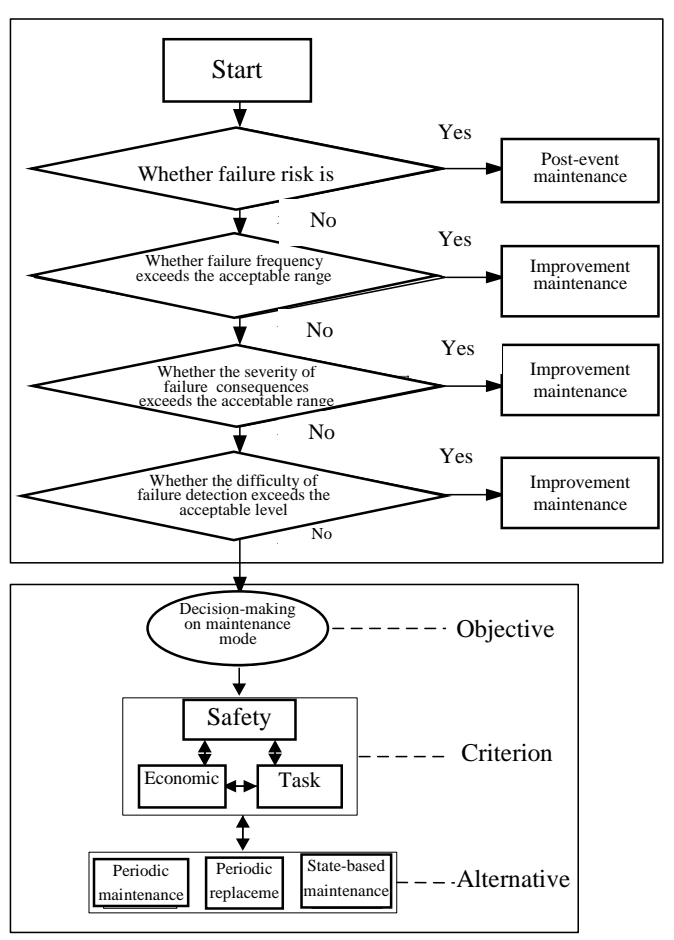

FIGURE II. LOGICAL JUDGMENT DIAGRAM FOR DECISION-MAKING RISKS OF MAINTENANCE MODE OF EQUIPMENT COMPONENTS WITHIN TASK CYCLE
The logical judgment is simple to implement, and able to gain the correct conclusion within a short period. Based on the analysis of the influence of maintenance mode on equipment failure risk in Table 1, the logical judgment diagram for decision-making risks of maintenance mode of equipment components within task cycle is designed by referring to the reliability-based logical judgment diagram with an aim to decide the selection of maintenance mode.

Analytic network process matches with the thinking habits of human while making a decision, and effectively deals with the issue involving no structure or semi-structure, so it is one of the commonest methods in the field of multiple attribute decision-making. If the maintenance mode of any component cannot be judged through logical judgment, it can take safety, task and economic risks as the decision-making indicators, so it is a typical multiple attribute decision-making issue. Decision-making indicators are interconnected with each other, and the evaluation features fuzzy language. Hence, fuzzy theory is combined with analytic network process to build a decision-making model for maintenance mode risks of equipment components within task cycle.

\section{Risk Model FOR MAINTENANCE MOdE OF EQUIPMENT COMPONENTS WITHIN TASK CYCLE}

\section{A. Risk Model for Maintenance Mode of Equipment Components within Task Cycle Based on Logical Judgment}

The logical judgment diagram for decision-making risks of maintenance mode of equipment components within task cycle is employed to make a judgment. For components with low failure risk, post-event maintenance is implemented. For components with high probability of failure occurrence, improvement maintenance is implemented. For components with high severity of failure, improvement maintenance is implemented. For high difficulty of failure detection, improvement maintenance is implemented. The maintenance for other components will be further judged. 


\section{B. Risk Model for Maintenance Mode of Equipment Components within Task Cycle Based on Fuzzy Analytic Network Process}

If the maintenance mode of any component cannot be determined through logical judgment, we take the safety, task and economic risks as the decision-making criteria, take three maintenance modes including preventive periodic maintenance, preventive periodic replacement and state-based maintenance as the alternatives, and take the optimal maintenance mode as the decision-making objective, so as to build a risk model for maintenance mode of equipment components within task cycle based on fuzzy analytic network process. To be specific, it contains 7 steps as follows:

1) Construct the fuzzy superiority matrix of maintenance mode based on risk evaluation indicators:Through the pairwise comparison of preventive periodic maintenance, preventive periodic replacement and state-based maintenance based on decision-making indicators, the superiority matrix of each maintenance mode is obtained, i.e. $F_{S}=\left(\tilde{x}_{i j}\right)^{S}$, $F_{T}=\left(\tilde{x}_{i j}\right)^{T}$ and $F_{C}=\left(\tilde{x}_{i j}\right)_{33}^{C}$. The corresponding relations in the conversion of fuzzy language and fuzzy numbers are presented in Table 2.

TABLE II. CONVERSION OF FUZZY NuMBERS FOR MAINTENANCE MODE SUPERIORITY BASED ON RISK EVALUATION INDICATORS

\begin{tabular}{|c|c|c|}
\hline No. & Fuzzy Language & Triangular Fuzzy \\
\hline 1 & Equally superior & $(1,1,1)$ \\
\hline 2 & Basically equally superior & $(1 / 2,1,3 / 2)$ \\
\hline 3 & Slightly superior & $(1,3 / 2,2)$ \\
\hline 4 & Superior & $(3 / 2,2,5 / 2)$ \\
\hline 5 & Much superior & $(2,5 / 2,3)$ \\
\hline 6 & Very much superior & $(5 / 2,3,7 / 2)$ \\
\hline
\end{tabular}

$$
F=\left(\tilde{x}_{i j}\right)_{3 \times 3}=\left[\begin{array}{ccc}
(1,1,1) & \left(x_{12}, y_{12}, z_{12}\right) & \left(x_{13}, y_{13}, z_{13}\right) \\
\left(x_{21}, y_{21}, z_{21}\right) & (1,1,1) & \left(x_{23}, y_{23}, z_{23}\right) \\
\left(x_{31}, y_{31}, z_{31}\right) & \left(x_{32}, y_{32}, z_{32}\right) & (1,1,1)
\end{array}\right]
$$

2) Construct a fuzzy weight matrix of risk evaluation indicators:Through asking the experts about the importance of safety risk, task risk and economic risk through pairwise comparison, the weight matrix of risk evaluation indicators is obtained, i.e. $F_{P W}=\left(\tilde{x}_{i j}\right)^{P W}$. The corresponding relations in the conversion of fuzzy language and fuzzy numbers are as presented in Table 2.

3) Construct a fuzzy relational matrix of risk evaluation indicators for maintenance mode:By comparing the relations among safety, task and economic risks of maintenance mode pairwise, the modified weight matrix of risk evaluation indicators for maintenance mode is obtained, i.e. $F_{T C}=\left(\tilde{x}_{i .}\right)^{T C}$, $F_{E C}=\left(\tilde{x}_{i j}\right)^{E C}$ and $F_{C C}=\left(\tilde{x}_{i j}\right)^{C C}$. The corresponding relations in the conversion of fuzzy language and fuzzy numbers are presented in Table 3.
TABLE III. TABLE 3 CONVERSION OF FUZZY NUMBERS FOR MODIFIED WEIGHTS OF RISK EVALUATION INDICATORS

\begin{tabular}{|c|c|c|}
\hline No. & Fuzzy Language & Triangular Fuzzy \\
\hline 1 & Absolutely Superior & $(5 / 2,3,7 / 2)$ \\
\hline 2 & Extremely Superior & $(3 / 2,2,5 / 2)$ \\
\hline 3 & Much Superior & $(1,3 / 2,2)$ \\
\hline 4 & Slightly Superior & $(1 / 2,1,3 / 2)$ \\
\hline 5 & Superior & $(1 / 2,2 / 3,1)$ \\
\hline 6 & Not Much Superior & $(2 / 5,1 / 2,2 / 3)$ \\
\hline 7 & Not Superior & $(2 / 7,1 / 3,2 / 5)$ \\
\hline
\end{tabular}

4) Convert fuzzy superiority matrix into numerical superiority matrix:

The following calculation is employed to convert fuzzy superiority matrix into numerical superiority matrix:

$$
\begin{gathered}
\Phi_{i}=\frac{D\left(\tilde{\mathrm{H}}_{i} \geq \tilde{\mathrm{H}}_{j} \mid j=1,2,3, j \neq i\right)}{\sum_{k=1}^{3} P\left(\tilde{\mathrm{H}}_{k} \geq \tilde{\mathrm{H}}_{j} \mid j=1,2,3, j \neq k\right)} \\
\tilde{\mathrm{H}}_{i}=\left(\gamma_{i}, \alpha_{i}, \beta_{i}\right)=\sum_{j=1}^{3} x_{i j} \otimes\left[\sum_{k=1}^{3} \sum_{j=1}^{3} x_{k j}\right]^{-1}
\end{gathered}
$$

$$
\begin{gathered}
P\left(\tilde{\mathrm{H}}_{i} \geq \tilde{\mathrm{H}}_{j}\right)=\sup _{y \geq x}\left[\min \left(\tilde{\mathrm{H}}_{i}(x), \tilde{\mathrm{H}}_{j}(y)\right)\right] \\
P\left(\tilde{\mathrm{H}}_{i} \geq \tilde{\mathrm{H}}_{j} \mid j=1,2,3, j \neq i\right)=\min _{j \in(1,2,3) i \neq j}\left[D\left(\tilde{\mathrm{H}}_{i} \geq \tilde{\mathrm{H}}_{j}\right)\right], i=1,2, \ldots, n \\
D\left(\tilde{\mathrm{H}}_{i} \geq \tilde{\mathrm{H}}_{j}\right)=\left\{\begin{array}{c}
1, \\
\frac{\gamma_{j}-\beta_{i}}{\left(\alpha_{i}-\beta_{i}\right)-\left(\alpha_{j}-\gamma_{j}\right)}, \alpha_{i} \leq \alpha_{j}, \gamma_{j} \leq \beta_{i}, j=1,2,3, j \neq i \\
0,
\end{array} \quad\right. \text { others }
\end{gathered}
$$

5) Construct an un-weighted super-matrix:

Based on the calculation of analytic network process, the unweighted super-matrix is obtained as follows:

$$
\Phi=\left[\begin{array}{ccc}
0 & \Phi_{12} & 0 \\
\Phi_{21} & \Phi_{22} & \Phi_{23} \\
0 & 0 & 0
\end{array}\right]
$$

In which, $\Phi_{12}$ is a $3 \times 3$ matrix representing the weight of maintenance mode relative to risk evaluation indicators. $\Phi_{21}$ is a $3 \times 3$ matrix representing the weight of risk evaluation indicator relative to maintenance mode. $\Phi_{22}$ is a $3 \times 3$ matrix representing the mutual influence of risk evaluation indicators. $\Phi_{23}$ represents the weight of risk evaluation indicator relative to objective. 


\section{6) Construct a weighted super-matrix:}

The eigenvector of each superiority matrix is calculated and normalized to obtain the weighted super-matrix:

$$
W=\left[\begin{array}{ccc}
0 & W_{12} & 0 \\
W_{21} & W_{22} & W_{23} \\
0 & 0 & 0
\end{array}\right]
$$

In which, $W_{12}$ is the eigenvector of $\Phi_{12}, W_{21}$ is the eigenvector of $\Phi_{21}$, and $W_{22}$ is the eigenvector of $\Phi_{22}$.

7) Construct an extreme super-matrix:The calculation of power method is employed to obtain the extreme super-matrix. In the extreme super-matrix, the maintenance mode with the highest weight is the optimal maintenance mode.

\section{CASE ANALysis}

Taking the fuel injector of fuel system in a diesel engine as an example, a model is built. The Delphi method is utilized to obtain the comparison matrix of maintenance mode based on decision-making indictors, the comparison matrix of decisionmaking indicators in terms of weight, and the superiority of risk evaluation indicators for each maintenance mode, through asking experts for opinions. results are shown in Table 4-10:

TABLE IV. Superiority of MAINTENANCE Mode By TAKING SAFETy RisK INDICATORS AS CRITERION

\begin{tabular}{|c|c|c|c|c|}
\hline Safety & & & & \\
\hline Strategy & CM & TBM & OCM & Superiority \\
\hline TBC & $(1,1,1)$ & $(2 / 3,1,2)$ & $(1 / 2,2 / 3,1)$ & 0.2916 \\
\hline TBR & $(2 / 3,1,2)$ & $(1,1,1)$ & $(1 / 2,1,3 / 2)$ & 0.3884 \\
\hline CBM & $(1,3 / 2,2)$ & $(1 / 2,1,3 / 2)$ & $(1,1,1)$ & 0.3200 \\
\hline
\end{tabular}

TABLE V. SUPERIORITY OF MAINTENANCE MODE BY TAKING TASK RISK INDICATORS AS CRITERION

\begin{tabular}{|c|c|c|c|c|}
\hline Task & & & & \\
\hline Strategy & CM & TBM & OCM & Superiority \\
\hline TBC & $(1,1,1)$ & $(2 / 5,1 / 2,2 / 3)$ & $(1 / 2,2 / 3,1)$ & 0.0512 \\
\hline TBR & $(1 / 2,2 / 3,1)$ & $(1,1,1)$ & $(1,3 / 2,2)$ & 0.6091 \\
\hline CBM & $(1,3 / 2,2)$ & $(3 / 2,2,5 / 2)$ & $(1,1,1)$ & 0.3397 \\
\hline
\end{tabular}

TABLE VI. SUPERIORITY OF MAINTENANCE MODE BY TAKING ECONOMIC RISK INDICATORS AS CRITERION

\begin{tabular}{|c|c|c|c|c|}
\hline Economic & & & & \\
\hline Strategy & CM & TBM & OCM & Superiority \\
\hline TBC & $(1,1,1)$ & $(2 / 5,1 / 2,2 / 3)$ & $(2 / 5,1 / 2,2 / 3)$ & 0.2161 \\
\hline TBR & $(3 / 2,2,5 / 2)$ & $(1,1,1)$ & $(3 / 2,2,5 / 2)$ & 0.6046 \\
\hline CBM & $(2 / 3,1,2)$ & $(1 / 2,1,3 / 2)$ & $(1,1,1)$ & 0.1793 \\
\hline
\end{tabular}

TABLE VII. SUPERIORITY OF RISK EVALUATION INDICATORS

\begin{tabular}{|c|c|c|c|c|}
\hline $\begin{array}{c}\text { Decision- } \\
\text { making } \\
\text { Objective }\end{array}$ & Safety & Task & Economic & Superiority \\
\hline Criterion & $(1,1,1)$ & $(3 / 2,2,5 / 2)$ & $(1 / 2,1,3 / 2)$ & 0.4722 \\
\hline Safety & $(1 / 2,1,3 / 2)$ & $(1,1,1)$ & $(2 / 5,1 / 2,2 / 3)$ & 0.4289 \\
\hline Task & $(2 / 5,1 / 2,2 / 3)$ & $(3 / 2,2,5 / 2)$ & $(1,1,1)$ & 0.0989 \\
\hline Economic
\end{tabular}

TABLE VIII. SUPERIORITY OF PERIODICAL MAINTENANCE MOdE UNDER DIFFERENT CRITERIA

\begin{tabular}{|c|c|c|c|c|}
\hline TBC & & & & \\
\hline Criterion & Safety & Task & Economic & Superiority \\
\hline Safety & $(1,1,1)$ & $(2 / 3,1,2)$ & $(1 / 2,1,3 / 2)$ & 0.312 \\
\hline Task & $(2 / 7,1 / 3,2 / 5)$ & $(1,1,1)$ & $(2 / 7,1 / 3,2 / 5)$ & 0.337 \\
\hline Economic & $(5 / 2,3,7 / 2)$ & $(5 / 2,3,7 / 2)$ & $(1,1,1)$ & 0.351 \\
\hline
\end{tabular}

TABLE IX. SUPERIORITY OF PERIODICAL REPLACEMENT MODE UNDER DIFFERENT CRITERIA

\begin{tabular}{|c|c|c|c|c|}
\hline TBR & & & & \\
\hline Criterion & Safety & Task & Economic & Superiority \\
\hline Safety & $(1,1,1)$ & $(1 / 2,1,3 / 2)$ & $(1,3 / 2,2)$ & 0.398 \\
\hline Task & $(2 / 7,1 / 3,2 / 5)$ & $(1,1,1)$ & $(5 / 2,3,7 / 2)$ & 0.425 \\
\hline Economic & $(1 / 2,2 / 3,1)$ & $(2 / 3,1,2)$ & $(1,1,1)$ & 0.177 \\
\hline
\end{tabular}

TABLE X. SUPERIORITY OF STATE-BASEd MAINTENANCE MODE UNDER DIFFERENT CRITERIA

\begin{tabular}{|c|c|c|c|c|}
\hline OBM & & & & \\
\hline Criterion & Safety & Task & Economic & Superiority \\
\hline Safety & $(1,1,1)$ & $(2 / 5,1 / 2,2 / 3)$ & $(2 / 3,1,2)$ & 0.507 \\
\hline Task & $(1 / 2,1,3 / 2)$ & $(1,1,1)$ & $(1 / 2,2 / 3,1)$ & 0.302 \\
\hline Economic & $(1,3 / 2,2)$ & $(3 / 2,2,5 / 2)$ & $(1,1,1)$ & 0.191 \\
\hline
\end{tabular}

The un-weighted super-matrix is calculated as presented in Table 11.

TABLE XI. UN-WEIGHTED SUPER-MATRIX OF DECISION-MAKING ON MAINTENANCE MODE

\begin{tabular}{|c|c|c|c|c|c|c|c|c|}
\hline \multirow{2}{*}{\multicolumn{2}{|c|}{ Un-weighted Super-matrix }} & \multicolumn{3}{|c|}{ Strategy } & \multicolumn{3}{|c|}{ Criterion } & \multirow{2}{*}{ Objective } \\
\hline & & TBC & TBM & OBM & Safety & Availability & Cost & \\
\hline \multirow{3}{*}{ Strategy } & TBC & 0.0000 & 0.0000 & 0.0000 & 0.3120 & 0.3370 & 0.3510 & 0.0000 \\
\hline & TBM & 0.0000 & 0.0000 & 0.0000 & 0.3980 & 0.4250 & 0.1770 & 0.0000 \\
\hline & OBM & 0.0000 & 0.0000 & 0.0000 & 0.5070 & 0.3020 & 0.1910 & 0.0000 \\
\hline \multirow{3}{*}{ Criterion } & Safety & 0.2916 & 0.3884 & 0.3200 & 0.0000 & 0.5000 & 0.5000 & 0.4722 \\
\hline & Availability & 0.0512 & 0.6091 & 0.3397 & 0.5000 & 0.0000 & 0.5000 & 0.4289 \\
\hline & Cost & 0.2161 & 0.6046 & 0.1793 & 0.5000 & 0.5000 & 0.0000 & 0.0989 \\
\hline \multicolumn{2}{|c|}{ Objective } & & 0.0000 & 0.0000 & 0.0000 & 0.0000 & 0.0000 & 0.0000 \\
\hline
\end{tabular}


The calculation results of weighted super-matrix are presented in Table 12.

TABLE XII. WeIghted SUPER-MATRIX OF DECISION-MAKING ON MAINTENANCE MOdE

\begin{tabular}{|c|c|c|c|c|c|c|c|c|}
\hline \multirow{2}{*}{\multicolumn{2}{|c|}{$\begin{array}{l}\text { weighted } \\
\text { Super-matrix }\end{array}$}} & \multicolumn{3}{|c|}{ Strategy } & \multicolumn{3}{|c|}{ Criterion } & \multirow{3}{*}{$\begin{array}{c}\text { Objective } \\
0.0000\end{array}$} \\
\hline & & \multirow{2}{*}{$\begin{array}{c}\text { TBC } \\
0.0000\end{array}$} & \multirow{2}{*}{$\begin{array}{c}\text { TBM } \\
0.0000\end{array}$} & \multirow{2}{*}{$\begin{array}{c}\text { OBM } \\
0.0000\end{array}$} & \multirow{2}{*}{$\begin{array}{l}\text { Safety } \\
0.1348\end{array}$} & \multirow{2}{*}{$\begin{array}{c}\text { Availability } \\
0.04755\end{array}$} & \multirow{2}{*}{$\begin{array}{c}\text { Cost } \\
0.07245\end{array}$} & \\
\hline \multirow{3}{*}{ Strategy } & TBC & & & & & & & \\
\hline & TBM & 0.0000 & 0.0000 & 0.0000 & 0.1857 & 0.27078 & 0.31705 & 0.0000 \\
\hline & OBM & 0.0000 & 0.0000 & 0.0000 & 0.1776 & 0.16264 & 0.11440 & 0.0000 \\
\hline \multirow{3}{*}{ Criterion } & Safety & 0.0000 & 0.3481 & 0.2523 & 0.0000 & 0.25000 & 0.25000 & 0.4722 \\
\hline & Availability & 0.0000 & 0.6720 & 0.2581 & 0.2500 & 0.00000 & 0.25000 & 0.4289 \\
\hline & Cost & 1.0000 & 0.0000 & 0.5107 & 0.2500 & 0.25000 & 0.00000 & 0.0989 \\
\hline \multicolumn{2}{|c|}{ Objective } & 0.0000 & 0.0000 & 0.0000 & 0.0000 & 0.00000 & 0.00000 & 0.0000 \\
\hline
\end{tabular}

The extreme super-matrix is constructed as presented in Table 13.

TABLE XIII. EXTREME SUPER-MATRIX OF DECISION-MAKING ON MAINTENANCE MODE

\begin{tabular}{|c|c|c|c|c|c|c|c|c|}
\hline \multicolumn{2}{|c|}{ Extreme Super-matrix } & \multicolumn{3}{|c|}{ Strategy } & \multicolumn{3}{c|}{ Criterion } & \multirow{2}{*}{ Objective } \\
\cline { 2 - 9 } & & TBC & TBM & OBM & Safety & Availability & Cost & 0.0576 \\
\hline \multirow{3}{*}{ Strategy } & TBC & 0.0576 & 0.0576 & 0.0576 & 0.0576 & 0.0576 & 0.0576 & 0 \\
\cline { 2 - 9 } & TBM & 0.1636 & 0.1636 & 0.1636 & 0.1636 & 0.1636 & 0.1636 & 0.1636 \\
\cline { 2 - 9 }$y$ & OBM & 0.1013 & 0.1013 & 0.1013 & 0.1013 & 0.1013 & 0.1013 & 0.1013 \\
\hline \multirow{3}{*}{ Criterion } & Safety & 0.2042 & 0.2042 & 0.2042 & 0.2042 & 0.2042 & 0.2042 & 0.2042 \\
\cline { 2 - 10 } & Availability & 0.2318 & 0.2318 & 0.2318 & 0.2318 & 0.2318 & 0.2318 & 0.2318 \\
\cline { 2 - 10 } & Cost & 0.2415 & 0.2415 & 0.2415 & 0.2415 & 0.2415 & 0.2415 & 0.2415 \\
\hline \multicolumn{2}{|c|}{ Objective } & 0.0000 & 0.0000 & 0.0000 & 0.0000 & 0.0000 & 0.0000 & 0.0000 \\
\hline
\end{tabular}

Based on the calculation results in Table 13, it is obvious that fuel injector has the largest superiority through periodic replacement, i.e. $\frac{0.1636}{0.0576+0.1636+0.1013}=0.507$, so the optimal maintenance mode of fuel injector is periodic replacement.

\section{SUMMARY}

This paper analyzes the basic types of maintenance mode for equipment components within task cycle, and the influence of maintenance modes on the risk of equipment failure. By taking the failure risk and its factors as the decision-making indicators, the logical judgment method is utilized to create the logical judgment diagram for decisionmaking risks of maintenance mode for equipment components within task cycle. Based on the applicability of each

maintenance mode, the equipment applicable to post-event maintenance mode and improvement maintenance mode are selected. If any maintenance mode cannot be judged through logical judgment diagram, safety, task and economic risks are taken as the decision-making indicators, and fuzzy theory is combined with analytic network process to build a decisionmaking model for the risks of maintenance mode for equipment based on fuzzy analytic network process, and provide the method for deciding the optimal maintenance mode. This achievement will provide the support for decisionmaking in the preparation of equipment maintenance plan before execution of task, and help select the optimal maintenance mode to lower the failure risk and improve the task completion rate of equipment.

\section{ACKNOWLEDGMENT}

This work was supported by National Natural Science Foundation of China (71401171), PLA General Armament Department Pre-research Fund (9140A19030214JB11273), Military Universities 2110 Projects Phase III (4142D4557).

\section{REFERENCES}

[1] A. Jovanovic. Risk-based inspection and maintenance in power and process plants in Europe[J]. Nuclear Engineering and Design, 2003, 226:165-182.

[2] Deshpande V S, Modak J P. Maintenance strategy for tilting table of rolling mill based on reliability considerations.Reliability Engineering and System Safety.2003, 80(1):1-18.

[3] L. Wang, J. Chu, J. Wu. Selection of Optimum Maintenance Strategies Based on a Fuzzy Analytic Hierarchy Process[J]. International Journal of Production Economic, 2007,107:151-163.

[4] Jardine A K S, Joseph T, Banjevic D. Optimizing condition-based maintenance decisions for equipment subject to vibration monitoring[J]. Journal of Quality in Maintenance Engineering, 1999,5(3):192-202.

[5] Felix Redmill. Risk Analysis--a Subjective Process[J]. Engineering Management Journal, 2002,12(2):91-96.

[6] Zhao Mingxin, Lu Zongxiang, Wu Linlin, et al.Risk assessment based maintenance technology for electric transmission equipment[J]. Automation of Electric Power Systems, 2009,33(19):30-35.

[7] Kallen M J, Noortwijk J M V. Optimal periodic inspection of a deterioration process with sequential condition states[J]. International Journal of Pressure Vessels and Piping, 2006,83:249-255. 